\title{
Sildenafil May Have an Inhibition Effect on The TGFß1- Smad2/3 Pathway in PAH Rats
}

\author{
Yijia Xiang, Yonghui Wu, Shiyong Ye, Junchong Chen, Changhong Cai, Ning Zhu, Xuyong Zhao and \\ Chunlai Zeng* \\ Department of Cardiology, The Fifth Affiliated Hospital of Wenzhou Medical University, China \\ *Corresponding author: Chunlai Zeng, Department of Cardiology, The Fifth Affiliated Hospital of Wenzhou Medical University, \\ China
}

\section{ARTICLE INFO \\ Received: 幽 February 02, 2019 \\ Published: 㓞 February 26, 2019}

Citation: Yijia X, Yonghui W, Shiyong Y, Junchong C, Changhong C, Ning Z, Xuyong Z, Chunlai Z. Sildenafil May Have an Inhibition Effect on The TGF $\beta 1$-Smad2/3 Pathway in PAH Rats. Biomed J Sci \& Tech Res 15(2)-2019. BJSTR. MS.ID.002669.

Abbreviations: MCT: Monocrotaline; SILD: Sildenafil; PVR: Pulmonary Vascular Resistance; PAH: Pulmonary Arterial Hypertension; MMP: Matrix Metalloproteinase; RVSP: Right Ventricular Systolic Pressure; RI: Right Ventricular Hypertrophy Index

\begin{abstract}
Pulmonary artery remodeling plays a key role in the development of Pulmonary Artery Hypertension (PAH). And the TGF- $\beta 1$-Smad $2 / 3$ pathway takes part in this pathological process. It is well known that sildenafil improved the PAH by inhibiting the PDE5.However whether sildenafil could inhibit the TGF- $\beta 1$-Smad $2 / 3$ pathway is unknown. Thus, sixty rats were randomly divided into a control group (Control), a model group (MCT) and a sildenafil group (MCT+SILD). MCT solution $(60 \mathrm{mg} / \mathrm{kg})$ was subcutaneously injected to establish the model of Pulmonary Artery Hypertension in the MCT and MCT+SILD groups. Treatment with sildenafil $(50 \mathrm{mg} / \mathrm{kg})$ was orally administrated from the $22 \mathrm{nd}$ day for 2 weeks. At the end of the 5th week, the Right Ventricular Systolic Pressure (RVSP) was obtained, and the Right Ventricular Hypertrophy Index (RI) was determined as the ratio of the right ventricular weight to the left ventricular plus septal weight $(\mathrm{RV} / \mathrm{LV}+\mathrm{S})$. Western blots were used to determine the expression of TGF $\beta 1$, Smad2/3, P-Smad 2/3 and matrix metalloproteinase- 2 (MMP2) and matrix metalloproteinase-9(MMP9) in lung tissues. Results showed that TGFß1, Smad2/3, P-Smad 2/3, MMP2 and MMP9 expressions, as well as RVSP and RI, were decreased in the sildenafil treatment group. Sildenafil may have an inhibition effect on the TGFß1-Smad2/3 pathway in rats.
\end{abstract}

Keywords: MMP2/9; Pulmonary Arterial Hypertension; Smad2/3; Sildenafil; Tgf- $\beta 1$

\section{Introduction}

Pulmonary Arterial Hypertension (PAH) is a serious vascular disease characterized by elevated Pulmonary Vascular Resistance (PVR) and Pulmonary Arterial Pressure (PAP), resulting in progressive right heart hypertrophy and failure [1,2]. Recently, PAH has increasingly become recognized as a chronic proliferative disease, particularly because of the extensive vascular remodeling of the small pulmonary arteries [3,4]. Pathologically, the changes involve pulmonary arterial fibrosis and lumen stenosis [2].

At the molecular level, TGF- $\beta 1$ transduces messages from the cell membrane to nucleus by binding to its receptor and modulates the proliferation, migration and differentiation of various cells [5]. It has been proven that TGF- $\beta 1$ could induce the differentiation and migration of Pulmonary Artery Smooth Muscle Cells (PSMCs). In addition, the TGF- $\beta 1 /$ Smads signal pathway was activated in PAH, increasing its incidence $[6,7]$.
Sildenafil, a new PDE5 inhibitor, improved the exercise capacity and hemodynamics of PAH. Molecularly, sildenafil effectively decreases Pulmonary Arterial Pressure and improves its clinical symptoms by mediating the NO-cGMP pathway [8-12]. However, whether sildenafil suppresses the remodeling of PAH via the inhibition of TGF- $\beta 1 /$ Smads in PSMCs is unknown. Thus, this study was designed to investigate the role of sildenafil in PSMC remodeling in PAH via the inhibition of the TGF- $\beta 1 /$ Smads signal pathway.

\section{Materials and Methods}

\section{Animals and Ethics Statement}

In this study, male Sprague- Dawley (SD) rats, weighing between 200 and $250 \mathrm{~g}$, aged 6-8 weeks, were obtained from the Laboratory Animal Center of Zhejiang province (certificate no. 
SCXL (Zhe) 2008-0033). Animals were acclimated for at least one week at room temperature $\left(18-25^{\circ} \mathrm{C}\right), 55 \pm 5 \%$ humidity and a 12 -h light/dark cycle. The animals were given free access to a standard diet and tap water. All experimental procedures were approved by the Ethics Review of Animal Use Application of Fifth Affiliated Hospital of Wenzhou Medical University (Zhejiang, China) and were in accordance with the National Institutes of Health guidelines for the care and use of laboratory animals.

\section{Experimental Protocols and Treatment}

Sixty rats were randomly assigned to three groups. The control group (control, $\mathrm{n}=10$ ) was orally administered $0.9 \%$ saline. The model group (MCT, $\mathrm{n}=25$ ) received MCT with $0.9 \%$ saline. After three weeks, as previous study showed that the PAH was established [13], the sildenafil group (MCT+SILD, $\mathrm{n}=25$ ) received sildenafil (Plant Bio-Engineering Co, Ltd, Xi'an, China) at a dose of $50 \mathrm{mg} / \mathrm{kg}$ per day for two weeks. MCT (Sigma, USA) was dissolved in $1 \mathrm{~mol} / \mathrm{L} \mathrm{HCl}$, and the $\mathrm{pH}$ was adjusted to 7.20-7.40 with $1 \mathrm{~mol} / \mathrm{L}$ $\mathrm{NaOH}$. Rats in the MCT and MCT+SILD groups were subcutaneously injected with the MCT solution $(60 \mathrm{mg} / \mathrm{kg}$ ) once. Control rats were injected with an equal volume of saline.

\section{Hemodynamic and Cardiac Monitoring}

Rats were anesthetized with isoflurane via respiratory tract (Induction with concentration of $3-4 \%$ for two minutes and concentration of $2 \%$ for maintaining), followed by the insertion of a catheter (PE50 tubule) into the right ventricular cavity through the right jugular vein. After measuring the Right Ventricular Systolic Pressure (RVSP, $\mathrm{mmHg}$ ), the rats were sacrificed with $10 \%$ potassium chloride solution $(100 \mathrm{mg} / \mathrm{kg})$ administered to the inferior vena cava under the anesthetized condition of isoflurane. The heart was dissected, and the right ventricular hypertrophy index (RI) was assessed by the ratio of the right ventricular weight to the left ventricular plus septal weight $(\mathrm{RV} / \mathrm{LV}+\mathrm{S})$. Finally, the right lung was fixed in 10\% formaldehyde for histopathology studies, and the remainder was stored at $-80^{\circ} \mathrm{C}$.

\section{Histopathology}

After incubation for 72 hours, tissues from the upper lobe of the right lung were dehydrated via a graded alcohol series, embedded in paraffin, and cut into 3-5- $\mu \mathrm{m}$-thin sections. The tissue sections were stained with Hematoxylin and Eosin (HE), undergoing Masson staining and immunostaining with a-SMA. The medial film thickness in small arteries (diameter 25-100 $\mathrm{m}$ ) was visualized with a microscope.

\section{Western Blot}

Frozen lung tissues were homogenized in a Radio-Immunoprecipitation Assay (RIPA) lysis buffer (JRDUN Biotechnology(shanghai) co.Ltd, China) with protease and phosphatase inhibitors and centrifuged at $12000 \mathrm{~g}$ for 15 minutes. A bicinchoninic acid (Thermo, USA) reagent was used to measure the supernatant protein content. Extracts containing $80 \mu \mathrm{g}$ protein were electrophoresed and separated on $10 \%$ SDS-PAGE gels and transferred onto nitrocellulose membranes (Merck Millipore, Germany). The separated proteins were blocked with $5 \%$ skim milk at room temperature for one hour and incubated overnight at $4{ }^{\circ} \mathrm{C}$ with primary antibodies, including MMP2 (diluted 1:1000; Abcam, England), MMP9(diluted 1:1000; Abcam, England), TGF- $\beta 1$ (diluted 1:1000; Abcam, England), Smad2 (diluted 1:1000; Abcam, England), Smad3 (diluted 1:5000; Abcam, England), P-Smad2 (diluted 1:300;Abcam,England),P-Smad3(diluted 1:300; Abcam, England) and rabbit anti-GAPDH (diluted 1:1500; Cell Signaling Technology, USA). The membranes were then incubated with an HRP-conjugated secondary antibody (diluted 1:1000; Beyotime Institute of Technology, Shanghai, China) at room temperature for 1 hour. The bands were detected using a Super Signal ECL kit (Merck Millipore, Germany) in a Western blotting detection system (Bio-Rad, CA, USA) and quantified by density values, which were normalized to GAPDH.

\section{Statistical Analysis}

The data are presented as means \pm Standard Deviation (SD). Significant differences were determined by one-way ANOVA using SPSS19.0 statistical software (IBM) followed by a least significant difference test for multiple comparisons. Values were significant when $\mathrm{P}<0.05$.

\section{Results}

\section{Sildenafil Decreases Right Ventricular Systolic Pressure and Right Ventricular Hypertrophy}

At the end of the fifth week, RVSP was significantly increased in MCT-treated rats compared with the control group $(48.86 \pm 2.32 \mathrm{vs}$. $24.54 \pm 2.03, \mathrm{P}<0.05$ ), while RVSP was partially alleviated in the sildenafil group (37.58 \pm 2.53 , vs. the MCT group, $\mathrm{P}<0.05)$. Rats in the MCT group showed a significant right heart hypertrophy compared with the control group $(0.56 \pm 0.02$ vs. $0.29 \pm 0.02, \mathrm{P}<$ $0.05)$, which was attenuated by sildenafil $(0.48 \pm 0.01, \mathrm{P}<0.05)$. There were statistically significant differences in RVSP and RI among the three groups (Table 1).

Table 1: Sildenafil decreases right ventricular systolic pressure and right ventricular hypertrophy.

\begin{tabular}{|c|c|c|c|}
\hline Group & N & RVSP mmHg & RI \\
\hline Control & 8 & $24.54 \pm 2.03$ & $0.29 \pm 0.02$ \\
\hline MCT & 10 & $48.86 \pm 2.32^{*}$ & $0.56 \pm 0.02^{*}$ \\
\hline MCT+SILD & 12 & $37.58 \pm 2.53^{\#}$ & $0.48 \quad \pm 0.01^{\#}$ \\
\hline
\end{tabular}

Note: *P<0.05, MCT vs Control; \#P<0.05, MCT+SILD vs MCT. MCT: Monocrotaline; SILD: Sildenafil

RVSP: Right ventricular systolic pressure

RI: Right ventricular hypertrophy index

\section{Sildenafil Inhibits the Remodeling of Small Pulmonary Arteries}

Under the microscope, the media of small arteries were more obviously thickened with fibrosis in the model (MCT) group compared with the control group. These pathological changes were improved with sildenafil treatment (Figure 1). 


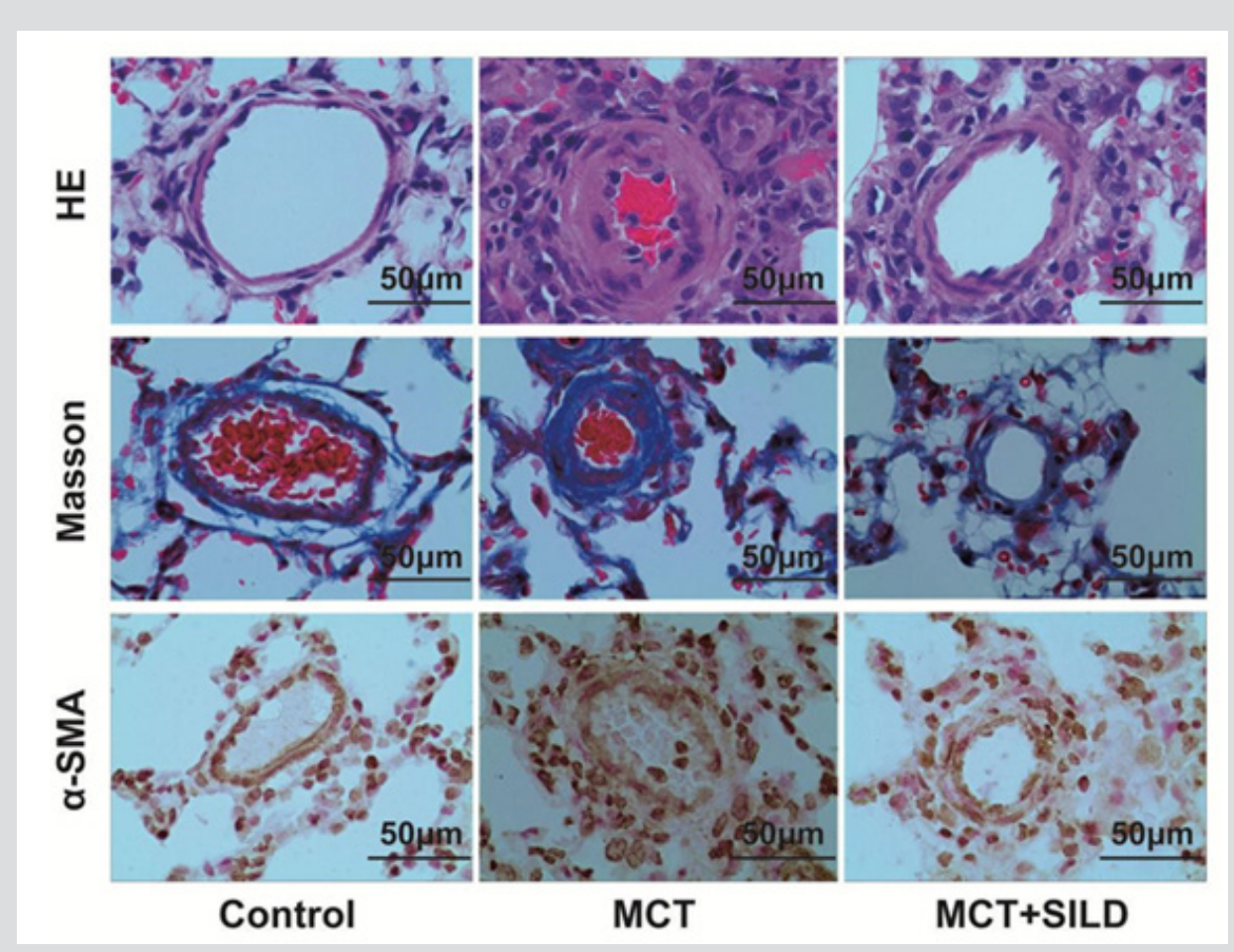

Figure 1: Sildenafil inhibits the small pulmonary arteries smooth muscle cells remodeling.

Note: Representative photomicrograph of pulmonary small artery remodeling indicated by HE staining, Masson staining and immunostaining with a-SMA in rat lung tissues (scan bar $=50 \mu \mathrm{m}, 400 \times$ ).

\section{Sildenafil Suppresses the Expression of TGF- $\beta 1$}

The results showed that MCT-injection caused a significant increase in the TGF- $\beta 1$ protein level. The relative level of TGF- $\beta 1$ was $0.57 \pm 0.03$ compared with the control group $(0.26 \pm 0.03, \mathrm{P}<$ $0.01, \mathrm{n}=6$ /group). Sildenafil treatment partially suppressed the expression of TGF- $\beta 1$ when compared with MCT injection alone $(0.40 \pm 0.02, \mathrm{P}<0.01)$ (Figure 2 ).

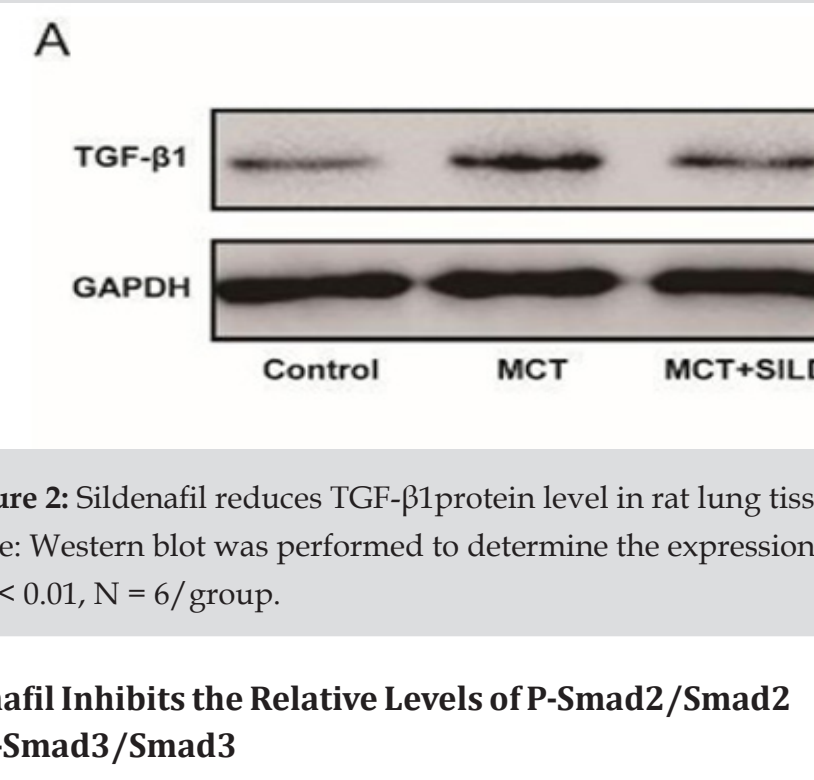

In this study, we found that MCT-induced PAH results in the increase of P-Smad2, P-Smad3, Smad2 and Smad3 in lung tissues. In addition, the ratio of P-Smad2/Smad2 was increased in the MCT

\section{Sildenafil Inhibits the Relative Levels of P-Smad2/Smad2 and P-Smad3/Smad3}

B

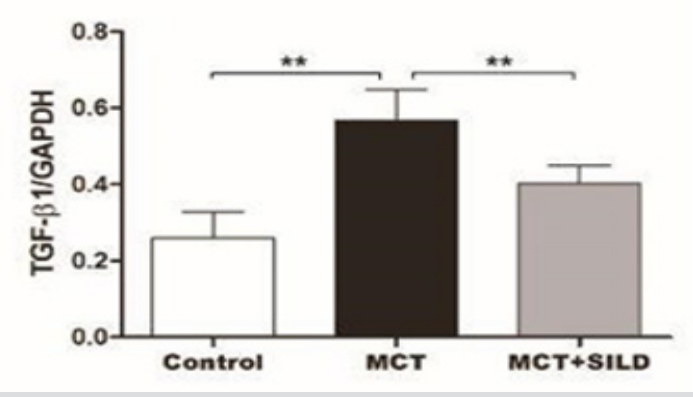

group compared with the control group ( $\mathrm{p}<0.01, \mathrm{n}=6 /$ group). The same result was obtained in the ratio of P-Smad3/Smad3(vs.MCT group, $\mathrm{p}<0.01, \mathrm{n}=6 /$ group). However, treatment with sildenafil reduced the levels of P-Smad2, P-Smad3, Smad2, and Smad3, and the ratio of P-Smad2/Smad2 and P-Smad3/Smad3 was also decreased respectively, ( $<<0.05, n=6 /$ group) (Figure 3). 
A

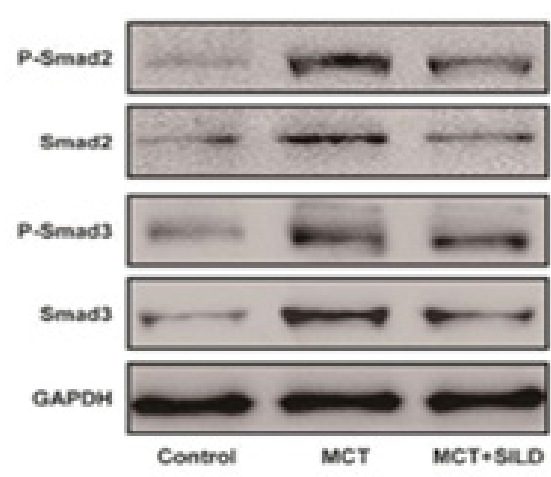

D

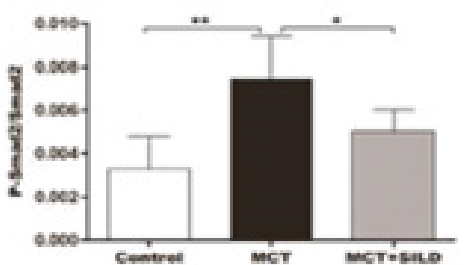

$\mathrm{F}$

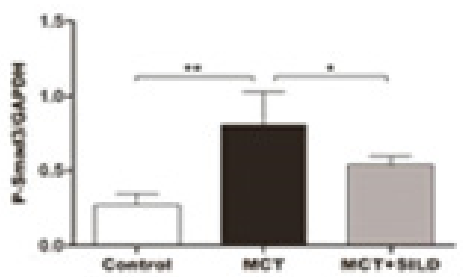

B

C

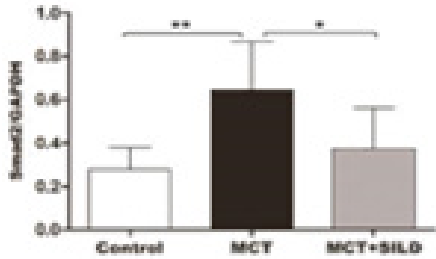

E

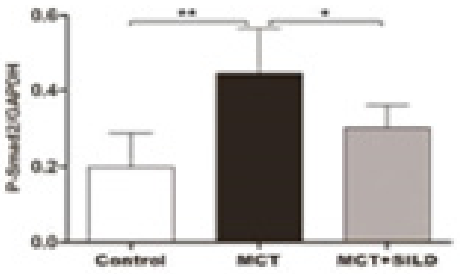

G
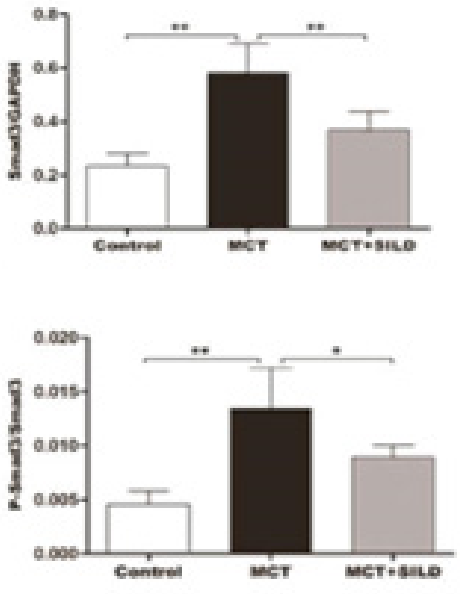

Figure 3: Sildenafil inhibits the relative level of P-Smand2/Smad2 and P-Smad3/Smad3.

Note: Western blot was performed to determine the expression levels of target proteins.

${ }^{*} \mathrm{P}<0.01,{ }^{*} \mathrm{P}<0.05, \mathrm{~N}=6$ / group

\section{Sildenafil Reduces the Expression of MMP2 and MMP9}

This study shows that the relative level of MMP2 was markedly increased in the MCT group from $0.36 \pm 0.06$ in the control group to $0.69 \pm 0.04(\mathrm{P}<0.01, \mathrm{n}=6 /$ group$)$, while the same change was obtained in the level of MMP9 in the MCT group $(0.68 \pm 0.03$ vs.0.36 \pm 0.05 , MCT vs. Sham, $\mathrm{p}<0.01, \mathrm{n}=6$ /group). However, sildenafil reduced the expression of MMP2 and MMP9 when compared with MCT injection alone $(0.49 \pm 0.02,0.56 \pm 0.03$, respectively, $\mathrm{P}<0.01$, n=6/group;) (Figure 4).

\section{A}

MMP2

GAPDH

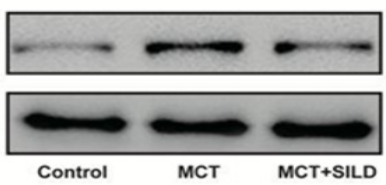

C

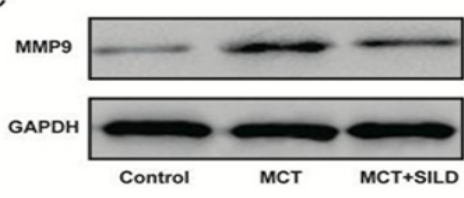

B

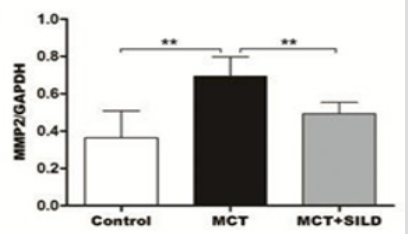

D

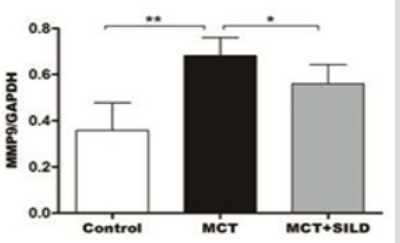

Figure 4: Sildenafil reduces expression of MMP2 and MMP9.

Note: Western blot was performed to determine the expression levels of target proteins.

${ }^{* *} \mathrm{P}<0.01$, ${ }^{*} \mathrm{P}<0.05, \mathrm{~N}=6$ / group. 


\section{Discussion}

PAH is characterized by pulmonary vascular remodeling, excessive vessels constriction and subsequently increased pulmonary pressure and eventually leading to right heart failure. In our study, Right Ventricular Systolic Pressure and right ventricular hypertrophy in the MCT group were significantly elevated, which strongly indicated that the model of MCT-related PAH was successfully established. Treatment of sildenafil significantly ameliorated the above adverse phenomena in accordance with the previous studies [14-17]. As we known that Fan Wu et al., have reported that sildenafil was able to reverse the increase in values of the wall thickness of the pulmonary arterioles induced by MCT [18], so in this study, the quantitative analysis of the wall thickness was not measured. Furthermore, at the molecular level, it reduced the levels of TGF- $\beta 1$, P-Smad2 / Smad2, P-Smad3/Smad3, MMP2and MMP9 in lung tissues.

It has been proven that Smooth Muscle Cell (SMC) and Endothelial Cell (EC) proliferation take part in the pathology of pulmonary vascular remodeling in pulmonary hypertension [1922]. TGF- $\beta$ is an important cytokine that is involved in regulating fibroblast proliferation, differentiation, migration and the formation of the extracellular matrix (ECM) [5]. There are three subtypes in the mammalian TGF- $\beta$ family which exist in the tissues of the lung, heart and other organs, among which TGF $-\beta 1$ is obviously related to fibrosis $[23,24]$. Study has confirmed that the TGF- $\beta 1$ can promote endothelial hyperplasia and enhance the deposition of the ECM in the process of vascular remodeling resulting from injury to the artery [25]. The combination of TGF - $\beta 1$ with its type I and II receptors on the membrane promotes Smads in the cytoplasm to form activated Smads. It is released from receptor complexes to form a trimer-containing two receptors-Smads and Smad4- and further regulates the expression of target genes in the nucleus [26]. As in previous studies, the relative levels of TGF- $\beta 1$, P-Smad/ Smad2 and P-Smad3/Smad3 were increased significantly in lung tissues in the MCT group [27-29]. This result indicated that the TGF- $\beta 1-S m a d 2 / 3$ signal pathway takes part in the procession of PAH. In addition, treatment with sildenafil partly reduced the levels of these target proteins in lung tissues. Thus, we may speculate that sildenafil may improve the PAH via the inhibition of TGF- $\beta 1$ Smad2/3 signal pathway at the molecular level, but this conclusion will in future be confirmed in cell research in vitro. Additionally, inhibitors of TGF- $\beta 1$-Smad2/3 signal pathway will also be used to certify the effect in animal model.

ECM is an important component in pulmonary vascular remodeling and its metabolism, mainly by way of Matrix Metalloproteinases (MMPs). The imbalance between MMPs and extracellular matrix metabolism promotes the formation of pulmonary hypertension. In the process of vascular remodeling, TGF- $\beta 1$ can enhance the deposition of the extracellular matrix, mainly for collagen type I and fibronectin [24]. TGF- $\beta 1$, Smad2, Smad3 can increase the synthesis of fibronectin, collagen and proteoglycans and reduce the decomposition of collagen protein, further resulting in an imbalance of the extracellular matrix and the deposition of collagen. Moreover, some MMPs can activate the extracellular TGF- $\beta 1$, such as MMP2 and MMP9 [30]. In this study, the relative levels of MMP2 and MMP9 were markedly increased in the lung tissues of MCT-induced rats, consistent with an increase of TGF- $\beta 1$, suggesting a complex relationship between the TGF- $\beta 1$ Smad2/3 pathway and MMPs. Our study showed that treatment with sildenafil suppressed the expression of MMP2 and MMP9 in lung tissues.

\section{Conclusion}

In conclusion, our study showed that sildenafil ameliorated MCT-induced pulmonary hypertension. And sildenafil may have an inhibition effect on the TGF- $\beta 1 / \operatorname{Smad} 2 / 3$ pathway.

\section{Acknowledgement}

This project was supported by the Medical and Health Science and Technology Project of Zhejiang Province (grant no.2015KYA244)

\section{References}

1. Ewert R, Opitz C, Wensel R, Winkler J, Höffken G, et al. (2000) Iloprost as inhalational and intravenous longterm treatment of patients with primary pulmonary hypertension: register of the Berlin Study Group for Pulmonary Hypertension. Z Kardiol 89(11): 987-999.

2. Chazova I, Loyd JE, Zhdanov VS, Newman JH, Belenkov Y, et al. (1995) Pulmonary artery adventitial changes and venous involvement in primary pulmonary hypertension. Am J Pathol 146(2): 389-397.

3. LJ Farber HW (2005) Mechanism of disease Pulmonary hypertension. Discov Med 5(25): 80-87.

4. Morrell NW, Adnot S, Archer SL, Dupuis J, Jones PL, et al. (2009) Cellular and molecular basis of pulmonary arterial hypertension. J Am Coll Cardiol 54: 20-31.

5. Roberts AB, Sporn MB (1993) Physiological actions and clinical applications of transforming growth factor-beta (TGF-beta). Growth Factors 8(1): 1-9.

6. Eickelberg 0, Morty RE (2007) Transforming growth factor beta/bone morphogenic protein signaling in pulmonary arterial hypertension: remodeling revisited. Trends Cardiovasc Med 17(8): 263-269.

7. N Dominguez Avila, G Ruiz Castañeda, J González Ramírez, N Fernandez Jaramillo, Jorge Escoto, et al. (2013) Over and underexpression of endothelin 1 and TGF-beta family ligands and receptors in lung tissue of broilers with pulmonary hypertension. Biomed Res Int 2013: 190382.

8. Wang RC, Jiang FM, Zheng QL, Li CT, Peng XY, et al. (2014) Efficacy and safety of sildenafil treatment in pulmonary arterial hypertension: A systematic review. Respir Med 108(3): 531-537.

9. Prasad S, Wilkinson J, Gatzoulis MA (2000) Sildenafil in primary pulmonary hypertension. N Engl J Med 343(18): 1342.

10. Lepore JJ, Maroo A, Pereira NL, Ginns LC, Dec GW, et al. (2002) Effect of sildenafil on the acute pulmonary vasodilator response to inhaled nitric oxide in adults with primary pulmonary hypertension. Am J Cardiol 90(6): 677-680.

11. Shekerdemian LS, Ravn HB, Penny DJ (2002) Intravenous sildenafil lowers pulmonary vascular resistancein a model of neonatal pulmonary hypertension. Am J Respir Crit Care Med 165(8): 1098-1102.

12. Ghofrani HA, Wiedemann R, Rose F, Schermuly RT, Olschewski H, et al. (2002) Sildenafil for treatment of lung fibrosis and pulmonary 
hypertension: a randomized controlled trial. Lancet 360(9337): 895900.

13. Sawamura F, Kato M, Fujita K, Nakazawa T, Beardsworth A (2009) Tadalafil A Long-Acting Inhibitor of PDE5, Improves Pulmonary Hemodynamics and Survival Rate of Monocrotaline-Induced Pulmonary Artery Hypertension in Rats. J Pharmacol Sci 111(3): 235-243.

14. Elias Al Mamun M, Satoh K, Tanaka S, Shimizu T, Nergui S, et al. (2014) Combination therapy with fasudil and sildenafil ameliorates monocrotaline-induced pulmonary hypertension and survival in rats. Circ J 78(4): 967-976.

15. Jasińska Stroschein M, Owczarek J, Łuczak A, Orszulak Michalak D (2013) The beneficial impact of fasudil and sildenafil on monocrotaline-induced pulmonary hypertensionin rats: A hemodynamic and biochemical study. Pharmacology 91(3-4): 178-184.

16. Yen CH, Tsai TH, Leu S, Chen YL, Chang LT, et al. (2013) Sildenafil improves long-term effect of endothelial progenitor cell-based treatment for monocrotaline-induced rat pulmonary arterial hypertension Cytotherapy 15(2): 209-223.

17. Mc Laughlin VV (2011) Looking to the future: A new decade of pulmonary arterial hypertension therapy.Eur Respir Rev 20(122): 262-269.

18. Wu F, Hao Y, Yang J, Yao W, Xu Y, et al. (2017) Protective effects of aloperine on monocrotaline-induced pulmonary hypertension in rats. Biomed Pharmacother 89: 632-641.

19. Budhiraja R, Tuder RM, Hassoun PM (2004) Endothelial dysfunction in pulmonary hypertension.Circulation 109(2): 159-165.

20. Katherine Howell, Robert J Preston, Paul Mc Loughlin (2003) Chronic hypoxia causes angiogenesis in addition to remodelling in the adult rat pulmonary circulation. J Physiol 547: 133-145.

21. Masri FA, Anand Apte B, Vasanji A, Xu W, Goggans T, et al. (2005) Definitive evidence of fundamental and inherent alteration in the phenotype of primary pulmonary hypertension endothelial cells in angiogenesis. Chest 128: 571S.

\section{ISSN: 2574-1241}

DOI: 10.26717/BJSTR.2019.15.002669

Chunlai Zeng. Biomed J Sci \& Tech Res

(C) This work is licensed under Creative Commons Attribution 4.0 License

Submission Link: https://biomedres.us/submit-manuscript.php
22. Voelkel NF, Douglas IS, Nicolls M(2007) Angiogenesis in chronic lung disease. Chest 131(3): 874-879.

23. LG Coker RK, Shahzeidi S, Lympany PA, Ddu Bois RM, Jeffery PK McAnulty RJ (1997) Transforming growth factors-beta 1, -beta 2, and -beta 3 stimulate fibroblast procollagen production in vitro but are differentially expressed during bleomycin-induced lung fibrosis. Am J Pathol 150: 981-991.

24. Jagirdar J, Lee TC, Reibman J, Gold LI, Aston C, et al. (1997) Immunohistochemical localization of transforming growth factor beta isoforms in asbestos-related diseases. Environ Health Perspect 105: 1197-1203.

25. Lambers C, Roth M, Zhong J, Campregher C, Binder P, et al. (2013) The interaction of endothelin-1 and TGF-beta1 mediates vascular cell remodeling. PLoS One 8(8): e73399.

26. Derynck R, Zhang YE (2003) Smad-dependent and Smad-independent pathways in TGF-beta family signalling. Nature 425(6958): 577-584.

27. Aikaterini JM, Chryssoula G, DL Oikonomidis, Agapi Vilaeti, MG Agelaki, et al. (2010) Transforming growth factor-beta inhibition attenuates pulmonary arterial hypertension in rats. Int J Clin Exp Med 3(4): 332 340.

28. Gao W, Shao R, Zhang X, Liu D, Liu Y, et al. (2017) Up-regulation of caveolin- 1 by DJ-1 attenuates rat pulmonary arterial hypertension by inhibiting TGF $\beta /$ Smad signaling pathway. Exp Cell Res 361(1): 192-198.

29. Xie J, Hu D, Niu L, Qu S, Wang S, et al. (2012) Mesenchymal stem cells attenuate vascular remodeling in monocrotaline-induced pulmonary hypertension rats. J Huazhong Univ Sci Technolog Med Sci 32(6): 810817.

30. McMahon S, Laprise MH, Dubois CM (2003) Alternative pathway for the role of furin in tumor cell invasion process. Enhanced MMP-2 levels through bioactive TGFbeta. Exp Cell Res 291(2): 326-339.

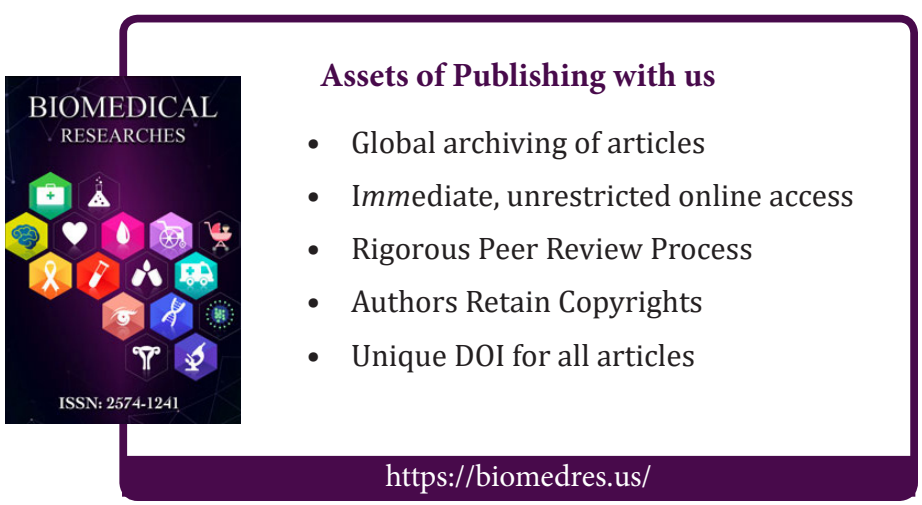

